Луговская Мария Владимировна

соискатель кафедры социальных технологий Белгородского государственного национального исследовательского университета

\section{КОРПОРАТИВНЫЕ ЗНАНИЯ В ПРАКТИКЕ УПРАВЛЕНИЯ ВУЗАМИ}

\section{Аннотация:}

В статье затрагивается тема использования корпоративных знаний в управлении организациями высшего образования. Представлены результаты авторского исследования «Корпоративные знания в практике управления вузом», проведенного в универcumeтах Белгородской, Воронежской и Курской областей с иелью оценить представления действующих в вузовском пространстве акторов о необходимости структуризации корпоративных знаний. Выявлены недостаточная сформированность представлений о корпоративных знаниях у респондентов, отсутствие эффективной системы распространения корпоративных знаний в организациях образования. Отмечено, что организационные условия управления корпоративными знаниями в вузах существенно деформированы. Данная деформация носит бюрократический характер и обусловлена чрезмерной формализованностью образовательного процесса. Различные группы респондентов (эксперты и администраторы) связывают дальнейшеe развитие системы корпоративных знаний ву$30 в$ с задачей их систематизации. В заключение предложены перспективные направления исследования проблемы, представлены практические рекомендации для вузов в сфере работы с корпоративными знаниями.

Ключевые слова:

образовательное сообщество, корпоративные знания, высшие учебные заведения, потенциал, групповые знания.

\section{Lugovskaya Maria Vladimirovna}

External PhD student Social Technologies Department, Belgorod State National Research University

\section{CORPORATE KNOWLEDGE IN UNIVERSITY MANAGEMENT}

Summary:

The paper discusses the role of corporate knowledge in higher education institutions management. The author presents the results of original research entitled Corporate Knowledge in University Management. The research was conducted at the universities of Belgorod, Voronezh and Kursk regions in order to assess the attitude of current university actors towards the need for corporate knowledge to be constructed. The respondents demonstrated the lack of understanding of corporate knowledge; the latter was ineffectively disseminated in educational organizations. Besides, the modalities regarding corporate knowledge management at the university were distorted. This deformation was of the bureaucratic nature and resulted from the extensive formalities of the academic process. Different groups of respondents (experts and administrators) think that further development of the university's corporate knowledge will be possible if this knowledge is systematized. In conclusion, the author presents the long-term objectives of future research in this regard and provides recommendations for the use of corporate knowledge at the university.

Keywords: educational community, corporate knowledge, higher education institutions, capacity, group knowledge.

В последние десятилетия особую значимость в социальном и экономическом развитии общества приобрели знания и интеллектуальные ресурсы. Это связано с действием ряда фундаментальных фракторов, и прежде всего с информационной революцией, интеллектуализацией используемых управленческих технологий, возникновением крупного сегмента рынка собственно интеллектуальных продуктов и услуг (патенты, лицензии, транзакции, консалтинг), быстрым темпом обновления знаний и необходимостью их постоянного пополнения. В результате происходящих изменений формируется новый вид управленческой деятельности - управление знаниями как значительным и постоянно растущим активом корпорации, в качестве которой в широком значении обычно рассматривается любая крупная организация, действующая преимущественно в экономической сфере либо оказывающая социальные услуги [1, с. 130].

В процессе решения своих задач вуз все чаще активно взаимодействует с традиционными корпоративными структурами, что не может не стимулировать конвергентные процессы между ними. Более того, как отмечают специалисты, университеты перенимают методы работы крупных экономических корпораций, участвуя «в начальной стадии» цикла производства и передачи знания, что для них было нехарактерно прежде. Усиление корпоративных начал в деятельности организации высшего образования, таким образом, укладывается в рамки общих тенденций развития современного социума, который становится все более «корпоративно структурированным», а корпоратократия играет в нем роль наиболее влиятельной элиты. Но включение в общую логику корпоративных процессов означает, что в ходе воспроизводства и конкуренции, которые все более жестко детерминируют функционирование вузов, они с неизбежностью должны использовать те корпоративные ресурсы, которые обеспечивают достижение целей. К числу таких ресурсов, органичных природе вуза, относятся корпоративные знания. 
Во многих российских вузах отсутствуют эфффективные системы управления корпоративными знаниями. По мнению М.А. Адаменко, «до сих пор не уделяется внимания полноте информирования работников о функционировании образовательного учреждения. Данное обстоятельство вполне может быть истолковано как свидетельство недооценки администрацией задачи развития персонала и в определенной степени пренебрежения ею. Однако пренебрежение развитием персонала в организации недопустимо, и особенно негативно оно проявляется в процессе управления корпоративными знаниями» [2, с. 33]. К.И. Шарова в своих трудах отмечает, что система управления знаниями не адаптирована к российским условиям и немногие компании положительно оценивают внедрение управления знаниями [3, с. 27]. По мнению М.К. Мариничевой, директора негосударственного образовательного учреждения «КМ Клуб: Практические знания», более половины отечественных учреждений, которые пробовали применить инструменты и методику управления знаниями, имели неудачный опыт [4]. Проблема заключается в нежелании обмениваться знаниями и опытом между коллегами и сотрудниками компаний.

Проблема знания интересовала американского социолога Д. Белла, который в работе «Социальные рамки информационного общества» подчеркнул огромную значимость теоретического знания в развитии общества, когда знания в своей систематической форме вовлекаются в практическую переработку ресурсов (в виде изобретения или усовершенствования) [5].

Одной из наиболее распространенных и общепринятых трактовок понятия «знание», используемых в современной российской и зарубежной научной литературе, является его понимание как синонима организованной информации, которую можно использовать специфическим образом (Х. Гейвин, Р.Л. Солсо и др.) [6, с. 37].

Как подчеркивает Э.Е. Зеленина, «...по данным современной статистики, профессорскопреподавательский состав вузов представлен в основном старшими возрастными группами (свыше 50-55 лет), чей менталитет фрормировался в иных условиях, кому значительно сложнее адаптироваться к нововременным процессам модернизации высшей школы и рыночным условиям ее деятельности» [7, с. 82]. К числу трудностей адаптации, на наш взгляд, относятся и проблемы освоения корпоративных знаний, в которых нередко делается акцент на нетрадиционных аспектах функционирования вуза. К ним, частности, относятся различные методики оценки работы преподавателей, технологии оформления документации, критерии рейтингования.

Таким образом, выявляется довольно очевидный парадокс: в организации, содержание деятельности которой определяется систематическим функционированием корпоративных знаний (а именно такой организацией является вуз), только меньшая часть работников имеет представление о технологиях их формирования и использования. На наш взгляд, это объясняется тем, что административный аппарат организации высшего образования продуцирует и использует корпоративные знания без участия их создателей (ученых и преподавателей), что типично для бюрократических систем. А современный вуз все более превращается в такую систему. В.П. Бабинцев, в частности, пишет: «Характерной чертой развития российского регионального вуза независимо от его статуса является бюрократизация научно-образовательного и воспитательного пространства. Она представляет собой конкретный случай проявления общей для новейшей истории тенденции возрастания роли и влияния административно-чиновничьего аппарата, универсализации применяемых им практик» [8, с. 30].

Нами было проведено социологическое исследование «Корпоративные знания в практике управления вузом» в вузах Белгородской, Воронежской, Курской областей. Опрос проводился по методике квотной выборки. Были выбраны одинаковые по статусу вузы: Белгородский государственный национальный исследовательский университет (НИУ «БелГУ»), Воронежский государственный университет (ВГУ), Юго-Западный государственный университет (ЮЗГУ). Данный набор объектов позволил охватить исследованием крупные государственные вузы в субъектах РФ и оценить представления действующих в вузовском пространстве акторов о необходимости структуризации корпоративных знаний. Акцент на диагностике именно университетской среды обусловлен тем, что именно университеты являются сегодня в России лидерами в решении проблем управления корпоративными знаниями.

Исследование проводилось методом анкетного опроса по трем группам респондентов: администрация вуза, преподаватели, научные сотрудники и эксперты. Выборочная совокупность административных работников вуза составила 225 респондентов. Данная группа представлена проректорами по различным направлениям, директорами институтов, руководителями и работниками административных структур. Преподаватели и научные сотрудники составили 455 респондентов. Одновременно был проведен формализованный опрос экспертов. Выборочная совокупность - 30 респондентов, которыми выступили работники органов государственного, муниципального управления и ученые.

Из проведенного исследования видно, что в большинстве вузов не сложилась система распространения корпоративных знаний. Работники получают информацию о них преимущественно 
из внешних источников либо в ходе неформального общения. Так, в качестве основных источников корпоративных знаний преподаватели определили: интернет-ресурсы (36,26 \%), рассказы коллег $(27,03)$, нормативные документы $(20,88)$, периодические издания $(18,90 \%)$. Более трети респондентов этой группы (36,04 \%) затруднились ответить на данный вопрос.

Однако, несмотря на то что у многих преподавателей и научных сотрудников отсутствует ясное представление как о целях, задачах, механизме функционирования, так и о содержании понятия «корпоративные знания», методах и формах их распространения и формирования, идея использования корпоративных знаний для функционирования вуза представляется весьма актуальной. Прежде всего она важна для администраторов, которые воспринимают корпоративные знания в основном как знания, обеспечивающие функционирование бюрократической системы.

Большинство опрошенных экспертов (53,33 \%) считают наиболее сложной проблему ресурсной обеспеченности процесса; 43,33 \% - несовершенство механизма разработки и внедрения информационных систем сосредоточения корпоративных знаний. 33,33 \% видят проблему в отсутствии научно обоснованного критерия оценки процесса формирования репозитория, 23,33 \% - в отсутствии стимулирования. 20 \% уверены, что проблема формирования корпоративных знаний вуза заключается в бюрократизме процедуры, 16,67 \% - в недостаточной готовности персонала к нововведениям. 13,33 \% выбрали вариант «отсутствие достаточного опыта».

Эксперты отмечают, чтобы корпоративные знания использовались на практике, необходимо создать репозиторий знаний и обеспечить возможность общего доступа к совокупности знаний (56,67 \% в обоих случаях). 50 \% опрошенных экспертов указали на необходимость обеспечения общего доступа к внутреннему обмену информацией. 40 \% сходятся во мнении: чтобы корпоративные знания применялись на практике и проблема имела решение, необходимо структурировать процесс получения знаний.

Анализ условий формирования, структуризации и использования знаний позволяет сделать заключение, что организационные условия управления корпоративными знаниями в вузах в настоящее время существенно деформированы. Эта деформация имеет бюрократическую природу и является следствием чрезмерной формализации образовательной деятельности. Множество вузовских структур, осуществляющих управление корпоративными знаниями, не всегда способны координировать работу, подчиняя ее решению стратегических задач.

Актуальность развития системы корпоративных знаний вуза подтверждается и экспертами, которые обосновывают это различными причинами. Так, 40 \% опрошенных указали, что данный процесс в управлении вузом позволит систематизировать знания, 36,67 \% - облегчит обмен информацией процесса образования, 13,33 \% - повысит уровень информированности участников образовательной деятельности.

Таким образом, и эксперты (в большей степени), и администраторы связывают необходимость развития системы корпоративных знаний в вузе и повышения уровня информированности акторов образовательного процесса с задачей их систематизации. Это является косвенным свидетельством того, что в высших образовательных учреждениях сложилось противоречие между наличием огромного массива информации, относящейся к организации образовательной, научной и социально-воспитательной деятельности, и ее недостаточной упорядоченностью. Следствиями этого зачастую являются дезориентация акторов, невозможность своевременно получить необходимые знания и оперативно их использовать.

В то же время включенность различных групп работников в инновационный процесс остается пока недостаточной. Это подтверждают исследования, проведенные В.А. Михайловым в Тверском государственном университете, на общую тему «Социологическое измерение готовности вуза к инновационному развитию» [9]. Так, опрос преподавателей, направленный на выявление уровня их осведомленности и включенности в инновационную деятельность, показал, что практически абсолютное большинство респондентов согласны с тем, что участие в осуществлении нововведений проявляется в основном без самостоятельной активности. 49 \% респондентов посчитали, что преподаватели и сотрудники университета вовлечены в активную инновационную деятельность в минимальной степени и что большинство из них работает по старым стандартам. 36 \% уверены, что вовлеченность сотрудников в инновационные процессы находится на среднем уровне. Лишь $15 \%$ респондентов заявили, что вовлеченность преподавательского корпуса выше среднего уровня.

Таким образом, опрос подтверждает, что корпоративные знания востребованы прежде всего в административном управленческом процессе в вузе. В этом проявляется их ограниченная функциональность. Во многом здесь кроется источник основных проблем формирования, генерации и использования корпоративных знаний.

Инновационный процесс, сопряженный с образовательным сообществом в период трансформации социума, стагнации образовательного процесса, неудавшейся реформы образования, 
продолжает репрезентировать уникальные действенные образовательные программы. Благодаря программам образовательной направленности происходит транспозиция целей образования - образование перестает быть целью и становится средством [10].

В процессе управления корпоративными знаниями возникает комплекс барьеров, определяющихся характером нерешенных проблем. К числу наиболее значимых относятся проблемы, характеризующие качество самих знаний; связанные с технологиями их разработки, распространения и использования; организационные проблемы.

Проведенное исследование позволяет сформулировать ряд практических рекомендаций для вузов. В частности, организациям высшего образования следует:

- разработать и реализовать дорожную карту формирования системы управления корпоративными знаниями;

- подготовить и принять административный регламент, определяющий процедуры производства, распространения и использования корпоративных знаний, в том числе порядок их продажи внешнему клиенту;

- на основе вузовских библиотек создать центры управления корпоративными знаниями;

- создать в библиотеках репозитории корпоративных знаний;

- стимулировать разработку маркетинговых проектов, направленных на организацию системы продажи корпоративных знаний внешним потребителям.

Проведенный анализ позволяет определить направления дальнейшего исследования проблемы. К ним относятся:

- управление всеми знаниями учреждения, в том числе и недокументируемой (нефрормализованной) информацией;

- создание системы обмена опытом, что позволит сотрудникам самостоятельно обмениваться и управлять знаниями в общедоступной среде;

- влияние интеллектуального капитала сотрудников на дальнейшее эфффективное развитие учебного заведения;

- уточнение оснований структурирования корпоративных знаний и критериев решения данной задачи;

- оценка рисков, возникающих в ходе управления корпоративными знаниями;

- анализ бюрократических барьеров, препятствующих эффективному управлению корпоративными знаниями;

- разработка технологий изменения интенции акторов вузовского пространства к участию в управлении корпоративными знаниями.

\section{Ссылки:}

1. Василенко Л.А. Информационно-коммуникационные аспекты профессионального развития государственных деятелей // Коммуникология. 2013. Т. 2, № 2. С. 129-133.

2. Адаменко М.А. Формирование образовательного пространства // Образование в России и за рубежом. 2015. № 7. C. 32-38.

3. Шарова К.И. Мировые тенденции управления знаниями в контексте становления постиндустриального общества // Вестник Полоцкого государственного университета. 2011. № 13. С. 25-28.

4. Мариничева М.К. Управление знаниями на 100 \%. М., 2008. 314 с.

5. Белл Д. Социальные рамки информационного общества // Новая технократическая волна на Западе. М., 1986. C. $330-342$.

6. Гейвин Х. Когнитивная психология. СПб., 2003. 272 с.

7. Зеленина Э.Е. Оценка профессиональной деятельности молодого преподавателя высшей школы в контексте личностного и профессионального развития // Известия Российского государственного педагогического университета им. А.И. Герцена. 2008. № 63-2. С. 82-87.

8. Бабинцев В.П. Бюрократизация регионального вуза // Высшее образования в России. 2014. № 2. С. 30-37.

9. См., например: Михайлов В.А. Инновационный потенциал регионального вуза: социологический аспект [Электронный ресурc]. URL: http://innoj.tversu.ru/Vipusk4(5)2014/2Михайлов.pdf (дата обращения: 13.04.2018).

10. Mayer R.V. Assimilation and Forgetting of the Educational Information: Results of Imitating Modelling // European Journal of Contemporary Education. 2017. Vol. 6, no. 4. P. 739-747. https://doi.org/10.13187/ejced.2017.4.739.

\section{References:} sian).

Adamenko, MA 2015, 'Development of educational space', Obrazovaniye v Rossii i za rubezhom, no. 7, pp. 32-38, (in Rus-

Babintsev, VP 2014, 'Bureaucratization of a regional university', Vyssheye obrazovaniye, no. 2, pp. 30-37, (in Russian).

Bell, D 1986, 'The social framework of the information society', Novaya tekhnokraticheskaya volna na Zapade, Moscow, pp. 330-342, (in Russian).

Gavin, H 2003, Cognitive psychology, St. Petersburg, 272 p., (in Russian)

Marinicheva, MK 2008, Knowledge management is $100 \%$ complete, Moscow, 314 p., (in Russian).

Mayer, RV 2017, 'Assimilation and Forgetting of the Educational Information: Results of Imitating Modelling', European Journal of Contemporary Education, vol. 6, no. 4, pp. 739-747. https://doi.org/10.13187/ejced.2017.4.739. 
Mikhailov, VA 2018, Innovative capacity of the regional university: a sociological aspect, viewed 13 April 2018, $<$ http://innoj.tversu.ru/Vipusk4(5)2014/2Михайлов.pdf>, (in Russian).

Sharova, KI 2011, 'World trends in knowledge management in the context of the postindustrial society development', Vestnik Polotskogo gosudarstvennogo universiteta, no. 13, pp. 25-28, (in Russian).

Vasilenko, LA 2013, 'Information and communication aspects of the professional development of public officials', Kommunikologiya, vol. 2, no. 2, pp. 129-133, (in Russian).

Zelenin, EE 2008, 'Evaluation of the professional activity of a university lecturer in the context of personal and professional development', Izvestiya Rossiyskogo gosudarstvennogo pedagogicheskogo universiteta im. A.I. Gertsena, no. 63-2, pp. 82-87, (in Russian). 